\title{
A Research Note on the History of ITIN'S IMPLEMENTATION AND ADAPTATION in United States Tax Administration
}

Marquise Riley, Brendan Brown, John McKinley, and Eric Lewis

Marquise Riley, MPS (msr259@cornell.edu) and Brendan Brown, MPS (bfb44@cornell.edu) are graduates of the Dyson School of Applied Economics MPS program. John McKinley, CPA, CGMA, JD. LLM (jwm336@cornell.edu) is a Professor of the Practice, Accounting and Taxation, Cornell SC Johnson College of Business, Cornell University, 117 Reservoir Drive, Ithaca, NY 14853. Eric Lewis, Ph.D. (eel33@cornell.edu) is an Associate Professor of the Practice, Accounting and Accounting Information Systems, Cornell SC Johnson College of Business, Cornell University, 117 Reservoir Drive, Ithaca, NY 14853. Correspondence regarding the paper should be addressed to John McKinley.

\begin{abstract}
An "ITIN" is an Individual Taxpayer Identification Number assigned by the IRS, for tax administration purposes, to those who are not entitled to a Social Security Number. In this paper, we identify the origins of the ITIN program and describe its implementation by the IRS. We also discuss the role that the ITIN fulfills in tax administration, along with some recent changes in the ITIN
\end{abstract}


laws as part of the Protecting Americans from Tax Hikes and Tax Cuts and Jobs Acts. This history and set of observations should serve as a starting point for future analysis and research into ITINs.

Keywords: compliance, history, ITINs, Internal Revenue Service, taxation

Data Availability: Data used in this paper are available from public sources.

DOI: http://dx.doi.org/10.15239/j.brcacadjb.2019.09.01.ja07

\section{INTRODUCTION}

The United States Department of Treasury and Internal Revenue Service (IRS) have long dealt with the difficulties of tracking taxpayer compliance, and ensuring the proper filing and payment of income taxes. The IRS continues to face numerous challenges in determining how to best implement a system that makes the tracking of taxpayer information both simple and effective. With over 4 million taxpayers each year requiring Individual Taxpayer Identification Numbers (ITINs) in order to comply with U.S. tax laws, the tasks of making ITINs more accessible to those seeking to file returns, and of eliminating any difficulties in the application process for both applicants and the IRS is daunting (National Taxpayer Advocate, 2015, p. 196). Numerous changes to ITIN application requirements and to related tax laws, especially with the recent passage of the Protecting Americans From Tax Hikes (PATH) Act of 2015 (part of the Consolidated Appropriations Act, 2016, P.L. 114-113) and Tax Cuts and Jobs Act (TCJA) (An Act for reconciliation pursuant to titles II and $\mathrm{V}$ of the concurrent resolution on the budget for fiscal year 2018, P.L. 115-97), can make compliance difficult for affected parties, while the penalties for failing to obey the published guidelines are severe. Economic consequences can include: late filing penalties, higher tax withholding, and/or the permanent loss of certain tax credits. 
In the sections that follow we address the history of identifying numbers in tax administration, with specific attention to the origins of the ITIN program. We also discuss the role that the ITIN fulfills in tax administration and how the ITIN program is implemented by the IRS.

\section{BACKground on ITINs AND Summary Statistics}

Each year more than 4 million tax returns are filed with the IRS by taxpayers using Individual Taxpayer Identification Numbers or "ITINs" (National Taxpayer Advocate, 2015, p. 196). Since the program's creation in 1996, it is estimated that the IRS has issued over 20 million ITINs to applicants from all over the world (National Immigration Law Center, 2017). From 2009 to 2014, the IRS received over 1 million new ITIN applications annually, with rejection rates ranging from 23 to 47 percent (National Taxpayer Advocate, 2015, p. 201, 207).

The National Taxpayer Advocate found the main reason for the rejection of many of these applications was that the process of mailing documents to the IRS "[resulted] in lost documents and additional work for the IRS." The Advocate argued that the requirement to include original documents in applications increased rejection rates, and highlighted that the "number one reason for [suspended] ITIN applications was that documentation did not meet IRS criteria" (National Taxpayer Advocate, 2016b, p. 248). The National Taxpayer Advocate based this assertion on its "2015 Annual Report to Congress" in Figure 1.18.6, Top Five Reasons for Suspended ITIN Applications. The five most frequently used suspense codes for ITIN applications were: S02 - Valid Documentation (i.e., did not meet IRS criteria), S26 - Passport, S03 - Identification documents must be an original or certified by the issuing agency, S36 - School Record, S30 - Medical Record; according to data submitted to the Advocate via an information request to the IRS (2015, p. 207-208).

Data collected in 2003 and 2012 by the National Taxpayer Advocate, and shared in its Annual Report; suggest that the largest share of applicants 
identify Mexico as their country of origin, at over 50 percent in 2001 (see, Appendix A, Figure 1) and 70 percent in 2012 (see, Appendix A, Figure 2) (National Taxpayer Advocate, 2003, p. 66 and National Taxpayer Advocate, 2012, p. 157). According to data that the authors received from the Internal Revenue Service, the share of applicants from Mexico has returned to roughly 50 percent in 2015 (Internal Revenue Service, 2017c).

Using data from Table 1.5.5. (p. 65 of the Report), we also configured a visual representation of the percentage of applications coming from each state. The result of this configuration is displayed in Appendix A, Figure 3 (2003). The three states with the largest share of ITIN applicants are California, Texas and New York, representing 27.1, 10.4 and 7.3 percent of applications, respectively (National Taxpayer Advocate, 2003, p. 65).

In 2015, taxpayers filing with ITINs paid roughly $\$ 8.2$ billion in income taxes (National Taxpayer Advocate, 2015, p. 200). While these figures are dwarfed by the amount of taxes paid by non-ITIN filers (e.g., SSN filers), it should also be recognized that while ITIN filers contribute to the tax base of the United States, in some cases they do not receive the benefits often associated with such contributions. For example, filing with an ITIN makes a taxpayer ineligible to receive the Earned Income Tax Credit (EITC), "even if their dependents have valid SSNs" (Internal Revenue Service, 2017a), or the child tax credit, as amended under the TCJA (Sec. 24(h)(7), as added by Act Sec. 11022(a)). In addition, the IRS states that "ITINs do not authorize a person to work in the U.S., nor do they provide eligibility for Social Security benefits" (2017a).

\section{The History of TAXPayer Identification Numbers in THE UNited STATES - Timeline}

In today's data driven society, the collection, organization and maintenance of tax records and other personal information depends on the use of numeric identifiers. For U.S. citizens, this is the social security number largely recognized as the universal, unique identifier in the United States. 
For those inside the United States who are not entitled to receive a social security number, the maintenance of their tax information depends on a related identifier, the Individual Taxpayer Identification Number (ITIN). However, it is of some note that the use of such identifying numbers has not always been an element of tax code implementation.

From the creation of the Revenue Act in 1913, until the early 1940s, a taxpayer identification number was not required on Form 1040 (individual income tax return). Examining the Form 1040 from 1913 thru 1941 reveals that during this early period, individual taxpayers wrote their home addresses on their tax returns in order to identify the return as their own (see, Appendix B, Figures 4 \& 5).

Beginning in 1942, the IRS added a designated line on the Form 1040 for a taxpayer's social security number (see, Appendix B, Figure 6). The authors were unable to identify a publication that explained the rationale for the change and its official purpose on the tax return. In 1944 and 1945, the first tax forms for use by non-U.S. citizens, the Forms 1040B and 1040NB were distributed by the IRS without a designation for any numerical identifier.

The Internal Revenue Service began mandating the use of identifying numbers in 1961 with the Congressional passage of Public Law 87-397. The law altered the Internal Revenue Code to renumber the previous section 6109 to section 6110. Additionally, in a new section 6109, the law codified rules pertaining to identifying numbers (P.L. 87-397, 1961). The principal change in the new law was the creation of subsection, A, of section 6109 , requiring taxpayers to furnish "such identifying number as may be prescribed for securing his proper identification" (P.L. 87-397, 1961). Essentially, the law granted the IRS the authority to require taxpayers to include their social security numbers on their returns. Public Law 87-397 contains other important highlights in subsections C and D. Subsection C states that "the Secretary or his delegate is authorized to require such information as may be necessary to assign an identifying number to any person" (P.L. 87-397, 1961). Subsection D, added later, specified that "the 
social security account number shall be used as the identifying number for such individual purposes of the law" (26 USC 6109 (d)).

From 1945 to 1967, the Forms 1040B and 1040NB were used to report income by Nonresident Aliens. In 1967, the Form 1040NR was created and distributed, replacing the Forms $1040 \mathrm{~B}$ and $1040 \mathrm{NB}$ as the Nonresident Alien return. In this new form, a designated line was included for the taxpayer's identification number, specifically, the social security number or the employer identification number (EIN).

In 1996, another major shift in the use of identification numbers took place with the creation of the Individual Taxpayer Identification Number (ITIN). The new numbering system was announced via the Federal Register in volume 60, page 30211. ITINs were to be used by taxpayers who were not entitled to a social security number from the Social Security Administration (60 FR 30211, 1995). The ITIN would reflect the same format as the social security number (i.e., 000-00-0000), but would be used for tax purposes only (60 FR 30211, 1995).

\section{THE INCE PTION OF THE ITIN SYSTEM}

The U.S. government recognized the need for a mechanism to organize, personalize, and maintain adequate records of taxpayer information as early as 1961. Examining the 1961 instructions to the Form 1040 (see, Exhibit B, Figure 7) reveals the legislative intent behind requiring taxpayers to furnish their social security numbers on their tax returns:

The Internal Revenue Service is installing an automatic data processing system which uses modern highspeed electronic equipment to improve and strengthen tax administration. Because many names are alike it is necessary to use numbers, in addition to names, to identify taxpayers in our electronic and other records. Since 130 million Americans already have Social Security numbers, it has been decided to use these numbers for tax purposes to save them the inconvenience of obtaining other numbers. Most taxpayers have been putting these numbers on their tax returns for 
many years, and will need only to continue this practice. At some time in the near future, those individuals who have income but do not have Social Security numbers will need to obtain account numbers. Details of this program will be announced from time to time. In the meantime, all those who are either employed or self-employed under the Social Security system should make sure that they have numbers and that they use their numbers on all tax documents. If you have previously obtained a Social Security number, but have no record of it, you should contact the nearest Social Security Administration office (1961).

In summary, the IRS was installing data processing capability to improve the recordkeeping of taxpayer returns. The operation of a data processing system necessitated the use of a unique identifier to distinguish between different records. Another pivotal element of the 1961 instructions is a statement by the IRS that "individuals who have income, but do not have social security numbers will need to obtain account numbers." This mandate invoked the authority P.L. 87-397 granted the IRS to "assign an identifying number to any person" (P.L. 87-397(c), 1961). The gap in this protocol - of assigning a number to a tax return with no associated social security number - would eventually necessitate the creation of the ITIN system.

\section{PREVIEW COMPLETE}

This completes the limited preview of this paper. Please visit the link below to purchase.

\section{Citation Information}

Riley, Marquise, Brendan Brown, John McKinley, and Eric Lewis. "A Research Note on the History of ITIN's Implementation and Adaptation in United States Tax Administration." The BRC Academy 
72 The BRC Academy Journal of Business Vol. 9, No. 1

fournal of Business 9, no. 1 (2019): 129-146. http://dx.doi.org/10.15239/ j.brcacadjb.2019.09.01.ja07

\section{Web Appendix}

A web appendix for this paper is available at: http://dx.doi.org/10.15239/ j.brcacadjb.2019.09.01.wa07 